\title{
Course and Standardized Exam Statistics in Mechanical Engineering
}

\section{Dr. Jessica Lofton, University of Evansville}

Dr. Lofton is an Assistant Professor of Mechanical Engineering at the University of Evansville. She is the Director for the OPTIONS in Engineering summer camps for middle school and high school girls.

\section{Dr. Jared T. Fulcher, University of Evansville}

Dr. Fulcher is an assistant professor of mechanical engineering at the University of Evansville. He is faculty adviser of the student chapter of the Society of Automotive Engineers (SAE) and faculty adviser to the UE SAE Baja Design Team. He is also the faculty adviser of Tau Delta Kappa, the University of Evansville Engineering Honor Society. He earned a B.S. in Mechanical Engineering at the University of Kentucky Extended Campus in Paducah, KY. He received both a M.S. and a PhD. in Mechanical Engineering from the University of Kentucky in Lexington, KY.

\section{Dr. Dick Blandford, University of Evansville}

Dick Blandford is the department chair of the Electrical Engineering and Computer Science Department at the University of Evansville. 


\section{Course and Standardized Exam Statistics in Mechanical Engineering}

\section{Introduction}

Engineering programs seek prospective students that demonstrate the potential to succeed in a field of study. Limiting access to those students that demonstrate a nominal level of preparedness can reduce strain on program resources and promote higher student retention rates. It is therefore important to identify admission criteria that effectively represent student potential for success in a program. Admissions criteria provide a list of requirements from which both prospective students and admissions gatekeepers can evaluate an applicant's preparedness for the program of study.

The admissions process for a student pursing a degree in Mechanical Engineering (ME) varies by institution. Students may be admitted to an ME directly from high school, in which case standardized exam scores (SAT/ACT) and high school GPA are often the primary measures of performance by which potential for success is evaluated. In other institutions, students are admitted to an ME program after completing certain pre-requisite courses within the undergraduate curriculum. Pre-requisite courses may include a series of math and science courses that provide a solid foundation for upper-level ME courses. In both cases, data-driven admission criteria may provide a more informed quantitative measure of student potential for success.

Others studies have examined relationships between various measures of performance and student success in college [1], [2], [3], [4]. A study conducted at the University of Michigan's College of Engineering concluded that ACT math scores were better predictors of students earning passing grades in first term freshman engineering courses than ACT science and SAT math scores [5]. Alternatively, a study including data from five Texas universities suggests that high school class rank is a superior predictor of college performance [6]. However, it is not uncommon for high schools to not report class rankings on high school transcripts. Still other studies suggest high school GPA or first semester performance can be a better indicator of college success.

In this study, measures of student performance at both the pre-college and early college level are examined. Pre-college measures of performance include high school GPA and SAT/ACT math score. Early college measures of performance include course grades and averaged GPAs of required courses in the first two years of the ME program at the University of Evansville (UE). Correlation data are presented for both pre-college and early college measures as indicators of student success in the ME program. The results are limited to three cohorts of graduates from the BSME program at UE. In this study, success is measured by GPA. 


\section{Mechanical Engineering Program Criteria}

The Mechanical Engineering program at the University of Evansville is designed to prepare students for entry level positions in the profession as well as further study at graduate programs. UE offers students a BS degree in an EAC-ABET accredited program, as well as five other engineering disciplines within the college. Students in the BSME program complete a rigorous, project-based curriculum [7] designed to engage students in the engineering design-build-test process during all four years of undergraduate study. Program highlights include small class sizes, access to faculty, and an integrated study abroad option.

The University of Evansville has implemented both admissions processes mentioned in the introduction. Students entering the program directly from high school must meet admission criteria for ME Lower Division. After completing the required Lower Division courses with a grade of C- or better, students must apply for ME Upper Division status to complete the final two years of study.

\section{Lower Division}

Lower Division is classified as the first two years of undergraduate study, which includes three calculus courses, differential equations, a calculus-based physics course with a lab component, a chemistry course with a lab component, and three foundational mechanics courses (Statics, Dynamics, and Mechanics of Materials). Additionally, Lower Division includes an introductory ME course, two ME integrated design courses with heavy project components, and a general education course required for all freshman at UE. Minimum high school preparation for Lower Division admission has been established to aid in accepting students that demonstrate potential for success in the program.

Lower Division admission criteria are [8]:

- Three-and-one-half years of mathematics with an average grade of B comprised of algebra, plane geometry, trigonometry, pre-calculus, and/or calculus

- Two years of science with an average grade of B including at least one year of chemistry with a laboratory

- SAT-I (MATH only) score of 560 or higher; SAT-R (MATH only) score of 580 or higher; or an ACT (MATH only) score of 26 or higher

- Four years of English

Applicants whose native language is not English must achieve a minimum TOEFL score of 550 (Paper Based Test), 79 (Internet Based Test), or 213 (Computer Based Test), or a minimum IELTS score of 6.5. As an alternate language consideration, a SAT-R (Reading and Writing) minimum score of 560 or an ACT (English) minimum score of 23 may be submitted in lieu of the TOEFL/IELTS requirements by students whose native language is not English.

Students that choose to enroll at UE but have not met the Lower Division requirements may apply for Lower Division acceptance into the ME program after demonstrating the following competencies: 
- Completion of MATH 105 (College Algebra) with a grade of B or better; or completion of MATH 221 (Calculus I) with a grade of C- or better

- Completion of all university required English Language courses (EL 102, 103, 106, 107, 110 , and/or 111) with a grade of B or better

\section{Upper Division}

After completing all Lower Division courses with a grade of C- or better, a student may apply for Upper Division status in the ME program. Students pursuing the BSME must be admitted to Upper Division by the ME program faculty before being permitted to enroll in any 300- or 400level ME course. Application for Upper Division admission is normally made at the beginning of the fourth semester of full-time study. The requirements for admission are the following [9]:

- Students must have completed a minimum of 60 credit hours with a minimum GPA of 2.5 and received a letter grade of $\mathrm{C}$ - or better in each of the following courses:

MATH 221 (Calculus I)

MATH 222 (Calculus II)

MATH 323 (Calculus III)

MATH 324 (Differential Equations)

CHEM 118 (Chemistry + lab)

PHYS 210 (Calculus-based Physics + lab)
ME 101 (Intro to Mechanical Engineering)

ME 197 (Integrated Design I)

ME 297 (Integrated Design II)

ENGR 212 (Statics)

ENGR 213 (Dynamics)

ENGR 232 (Mechanics of Materials)

- Students must obtain a C- or better in First-Year Seminar 112. Transfer students must meet the University catalog requirements for writing proficiency.

In addition to the Lower Division courses listed above, students also take two circuit courses during the first two years of the ME program. Students take EE 210 Circuits I and EE 215 Circuits II during their sophomore year.

Upper Division courses include fundamental courses, lab-based courses, technical electives, design-based courses, and a capstone engineering design experience. Students are required to take 13 common courses, one technical elective in thermal sciences, one technical elective in mechanics, and one technical elective of their choosing. The common courses are listed in Table 1 .

Table 1: Required ME Upper Division Courses

\begin{tabular}{|l|l|}
\hline ENGR 366 Fluid Mechanics & ME 360 Thermo/Fluid Dynamics Laboratory \\
\hline ENGR 390 Applied Engineering Mathematics & ME 362 Thermodynamics \\
\hline ME 318 Manufacturing Methods & ME 368 Heat Transfer \\
\hline ME 330 Materials Laboratory & ME 397 Integrated Design III \\
\hline ME 342 Machine Analysis & ME 452 System Modeling and Control \\
\hline ME 344 Machine Design & ME 495, 497 Professional Practice I, II \\
\hline
\end{tabular}

In the following analysis, pre-college measures of success are investigated as early indicators of potential for academic success in the first two years of the ME curriculum. Next, academic performance in the first two years, including individual courses and course groupings, are 
examined for correlation with academic success in the final two years of the ME program (Upper Division).

\section{Descriptive Statistics}

Information was limited to the last three graduating classes from the ME program. The total sample size was 61 students. The sample included 7 female students, 3 international students, and 3 transfer students. Further, SAT/ACT math scores were only available for 56 students of the total sample including 7 female students and 1 transfer student. High school GPA was only reported for 50 students of the total sample including 4 female students and 1 transfer student. The authors realize that the data are limited for this study and plan to keep expanding the data set with future graduating classes.

SAT scores were not available for all students in the sample. In the event that a student reported ACT score but no SAT score, the ACT math score was converted to an equivalent SAT math score using College Board's concordance tables [10]. It should be noted that there is error associated with converting between ACT and SAT test scores, however the concordance tables that were used achieved a 0.89 correlation between ACT and SAT math scores. With this high correlation the authors believe that using the concordance scores still predict student abilities to an acceptable level. Further, more students reported SAT scores than ACT scores, justifying the use of SAT score to reduce the introduction of additional error.

\section{Strength of Correlation}

Pearson's correlation coefficient (r) is a measure of how strongly one variable relates to another. The definition of the correlation coefficient is given by Equation (1).

$$
\mathrm{r}=\frac{\sum(\mathrm{x}-\overline{\mathrm{x}})(\mathrm{y}-\overline{\mathrm{y}})}{\sqrt{\sum(\mathrm{x}-\overline{\mathrm{x}})^{2}} \sqrt{\sum(\mathrm{y}-\overline{\mathrm{y}})^{2}}}
$$

A linear correlation analysis was performed using Microsoft Excel to determine the correlation coefficient between variables. The correlation coefficient ranges from -1 to +1 , with a value of zero meaning that the variables have no correlation and a value of 1 meaning perfect correlation. Table 2 summarizes the levels of strengths for correlation coefficient values [11]. The linear fit line is plotted with each data set for reference.

Table 2: Summary of levels of strength for correlation coefficient values.

\begin{tabular}{|c|c|}
\hline Correlation Coefficient & Strength \\
\hline $0<|\mathrm{r}| \leq 0.5$ & Weak \\
\hline $0.5<|\mathrm{r}|<0.8$ & Moderate \\
\hline$|\mathrm{r}| \geq 0.8$ & Strong \\
\hline
\end{tabular}




\section{Correlation Results}

\section{Pre-College Measures of Performance}

The first correlation analysis involved defining the relationship between pre-college measures of performance (SAT/ACT math score) and success in Lower Division and Upper Division courses taken during the mechanical engineering program. Figure 1 plots Calculus course GPA as function of SAT/ACT math scores.

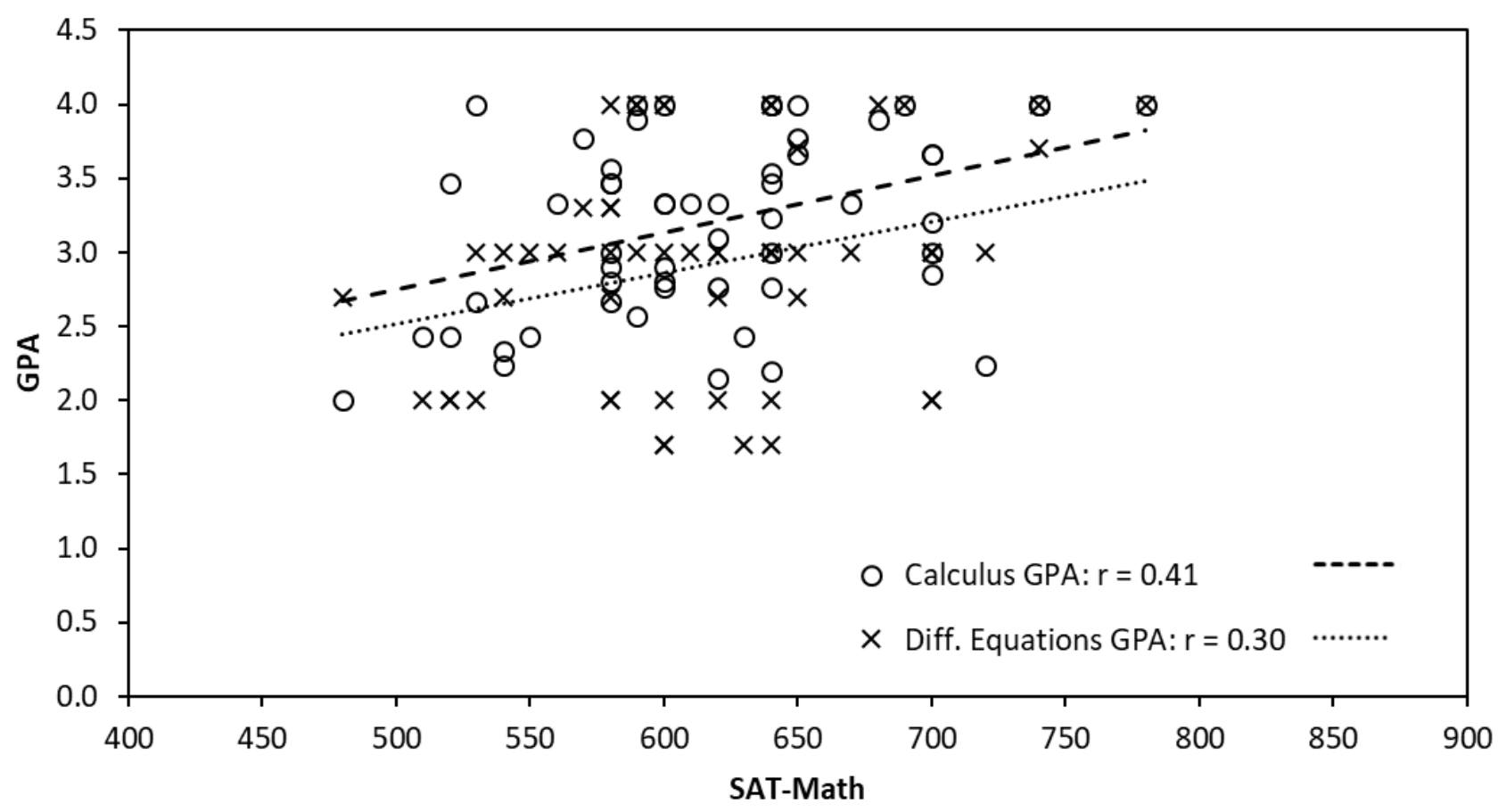

Figure 1: Math course GPA as a function of SAT math score.

The averaged GPA in Calculus I, Calculus II, and Calculus III and SAT/ACT math score had a correlation of 0.41. A correlation of 0.30 was found between GPA in Differential Equations and $\mathrm{SAT} / \mathrm{ACT}$ math score. In both cases a stronger correlation was expected based upon the SAT/ACT being a measure of scholastic aptitude and preparedness for college level math courses. Further a correlation of 0.42 and 0.34 exists between SAT/ACT math score and the averaged GPA in Physics I and Physics II and the GPA in Chemistry, respectively. Figure 2 plots mechanics course GPAs as function of SAT/ACT math scores. 


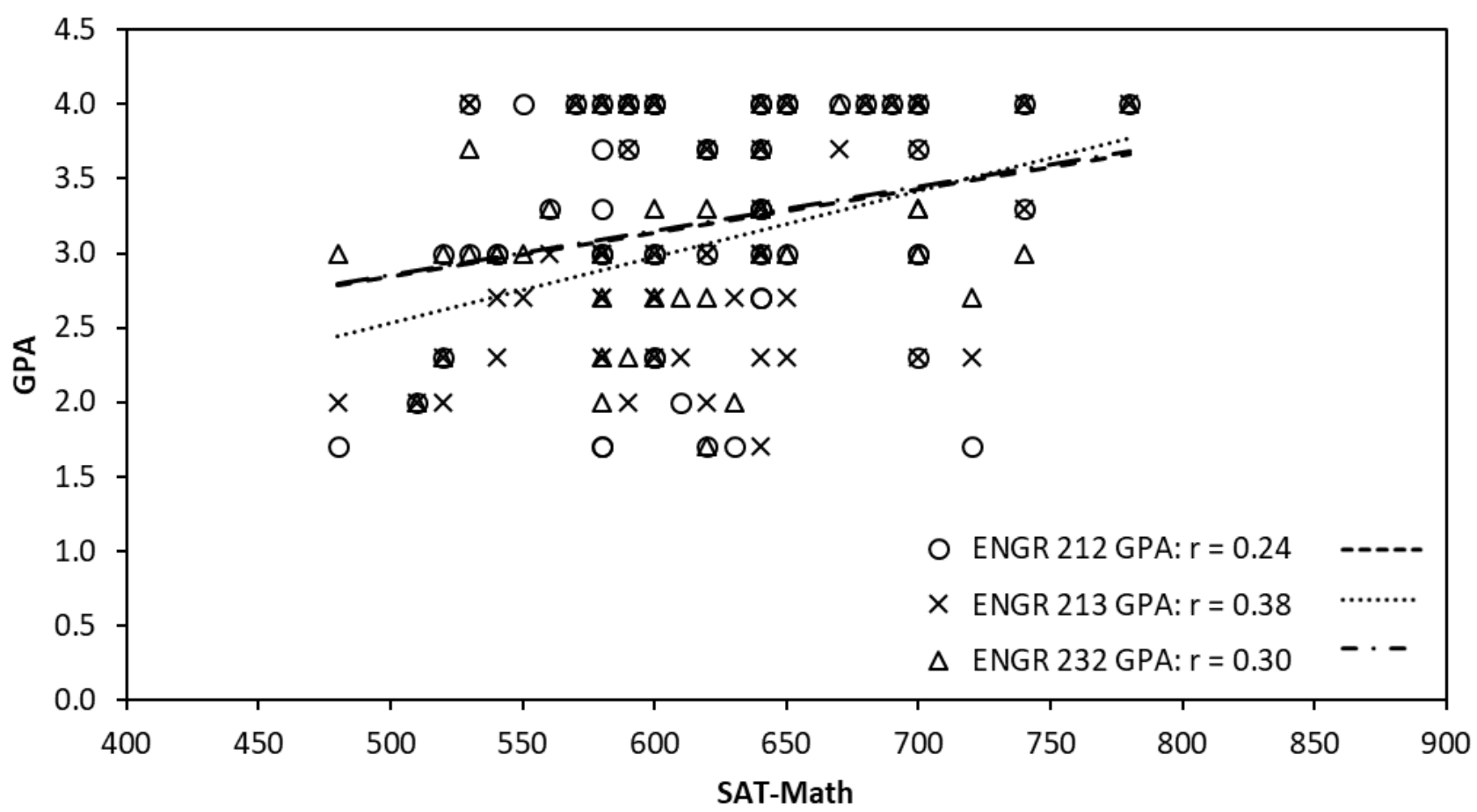

Figure 2: Mechanics courses GPA as a function of SAT/ACT math score.

The correlation between ENGR 212 (a sophomore statics course) and SAT/ACT math score was 0.24. ENGR 213 (a sophomore level dynamics course) and SAT/ACT math score had a correlation of 0.38. ENGR 232 (a sophomore level strength of materials course) had a correlation of 0.30 with SAT/ACT math score. The average GPA in the mechanics courses was calculated and a correlation of 0.34 was determined between the averaged Mechanics GPA and SAT/ACT math score. It was expected that the correlation between SAT/ACT math score and the mechanics courses would have been stronger, as the mechanics courses are math-intensive. Further, the average GPA in Circuits I and Circuits II was calculated and a correlation of 0.60 was found between the average Circuit GPA and SAT/ACT math score.

A final comparison was made between SAT/ACT math score and the overall ME Lower Division GPA and the overall ME Upper Division GPA. The ME Lower Division GPA includes math, physics, chemistry, and mechanics courses taken during the first two years of the mechanical engineering program. The ME Upper Division GPA includes the courses described in Table 1 and the ME technical electives that were taken. Figure 3 plots ME Lower Division GPA, ME Upper Division GPA, and University GPA as a function of SAT/ACT math score. 


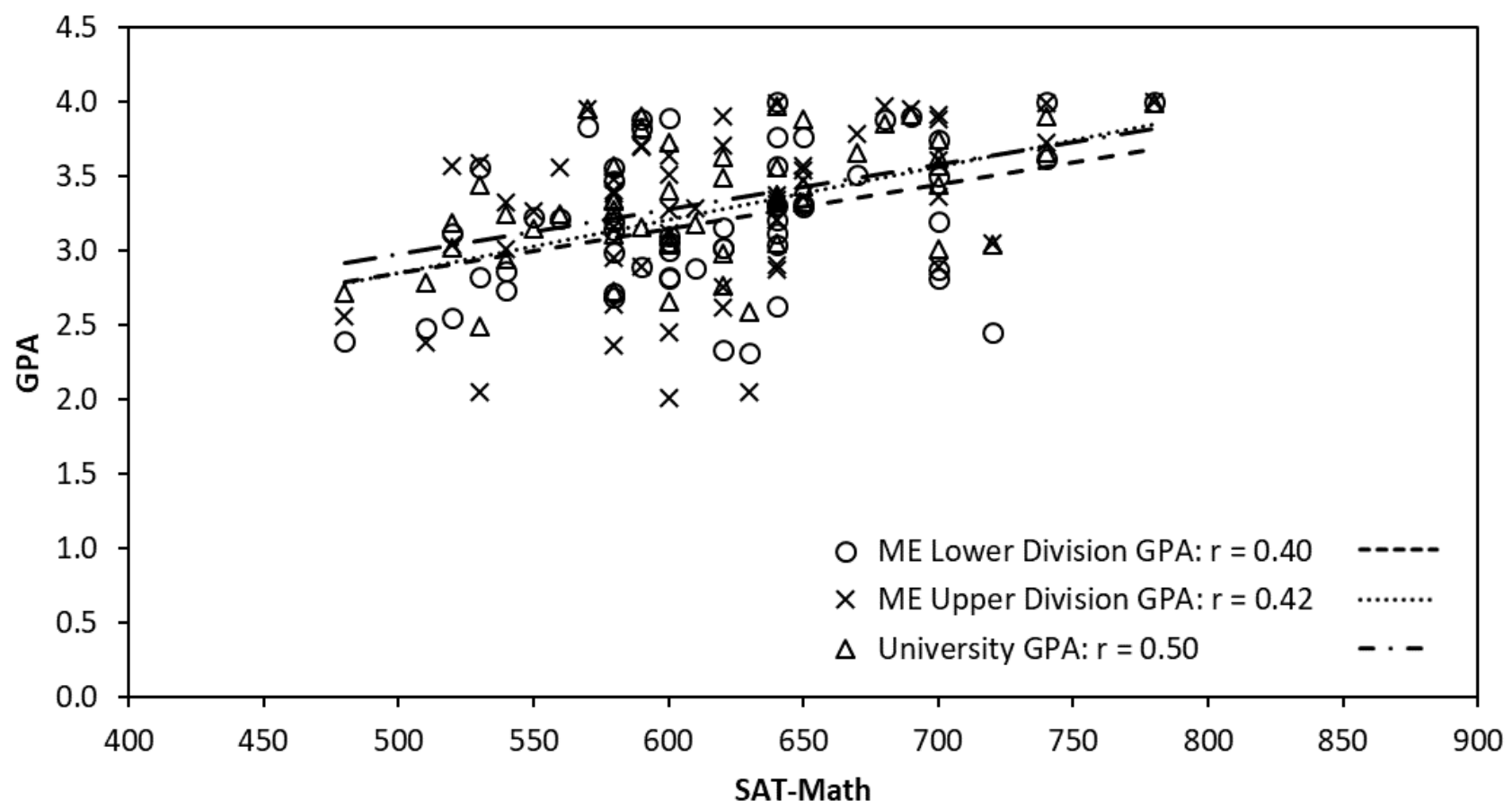

Figure 3: ME Lower Division GPA, ME Upper Division GPA, and University GPA as a function of SAT/ACT math score.

The correlation between ME Lower Division GPA and SAT/ACT math score is 0.40 with the correlation between ME Upper Division GPA and SAT/ACT math score being 0.42. The strongest correlation is between University GPA and SAT/ACT math score with a correlation coefficient of 0.50 .

Another pre-college measure of performance that was examined was high school GPA. The high school GPA was compared with ME Lower Division GPA and ME Upper Division GPA. Figure 4 plots ME Lower Division GPA and ME Upper Division GPA as function of high school GPA. The correlation between high school GPA and ME Lower Division GPA was 0.43. A correlation of 0.18 was determined between high school GPA and ME Upper Division GPA. Comparing the two pre-college measures of performance (SAT/ACT math score and high school GPA), it can be seen that SAT/ACT math has a much stronger correlation with Upper Division GPA. With the weak correlation between high school GPA and Upper Division GPA, high school GPA would be a weak predictor for success in the mechanical engineering program. 


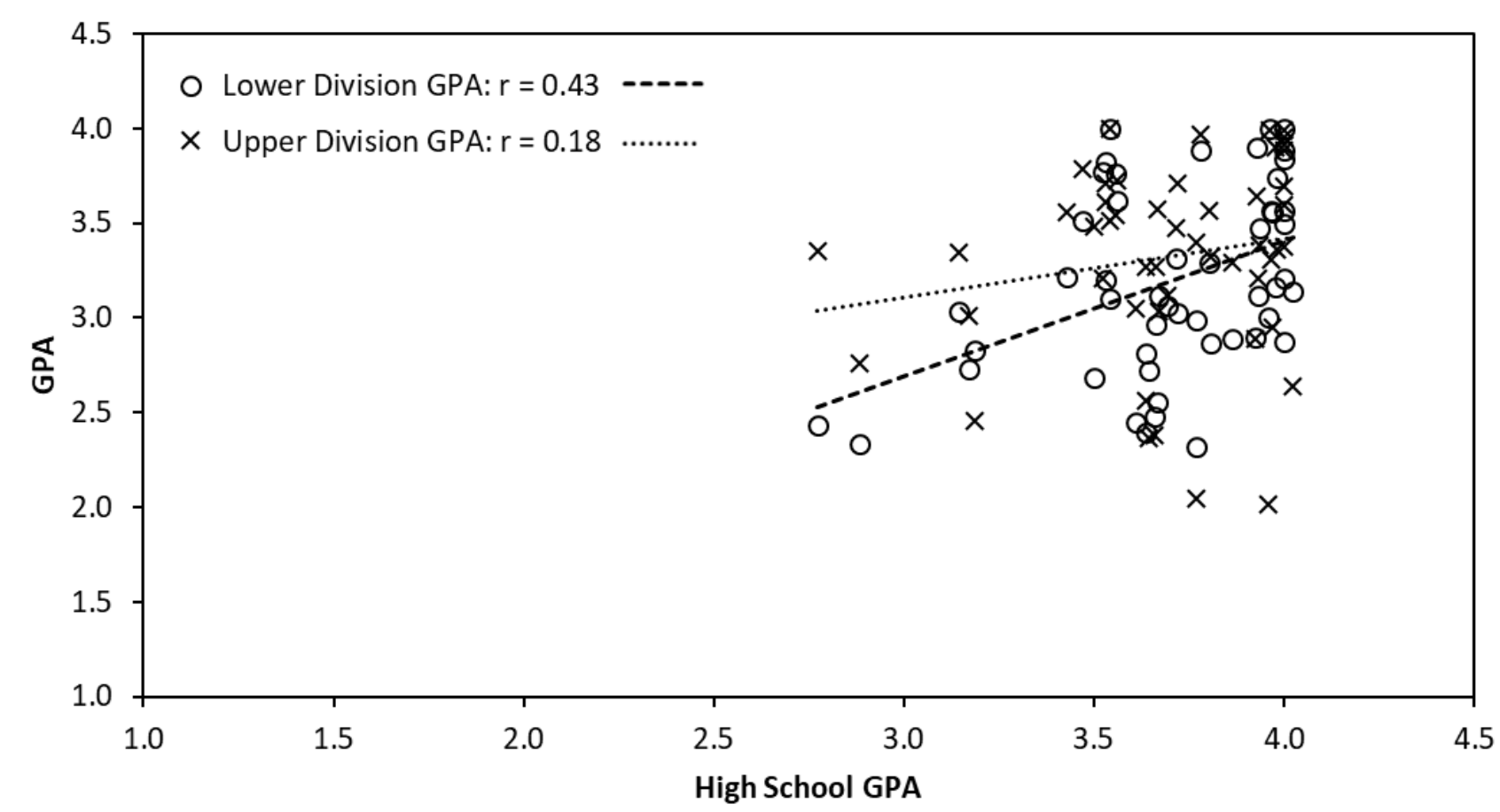

Figure 4: ME Lower Division GPA and ME Upper Division GPA as a function of high school GPA.

\section{Lower Division Measures of Performance}

The next part of the analysis examined the relationship between performance in courses taken during the first two years of the mechanical engineering program as part of ME Lower Division and ME Upper Division GPA. Figure 5 plots ME Upper Division GPA and math course GPAs. The averaged GPA in Calculus I, Calculus II, and Calculus III and ME Upper Division GPA had a correlation of 0.59. A correlation of 0.55 was found between GPA in Differential Equations and ME Upper Division GPA. Further, the correlation between ME Upper Division GPA and averaged GPA in Physics I and Physics II and GPA in Chemistry is 0.68 and 0.43, respectively.

A plot of ME Upper Division GPA and mechanics course GPAs is shown in Figure 6. The correlation between ENGR 212 (sophomore level statics course) and ME Upper Division GPA was 0.53 , the correlation between ENGR 213 (sophomore level dynamics course) and ME Upper Division GPA was 0.52, and the correlation between ENGR 232 (sophomore level strength of materials course) and ME Upper Division GPA was 0.61. An average GPA of these mechanics courses was calculated and the corresponding correlation between the average mechanics GPA and ME Upper Division GPA was 0.62. Further the correlation between the averaged GPA in Circuits I and Circuits II and ME Upper Division GPA was 0.57. These correlations provide evidence for these courses be foundational for success in higher level courses. 


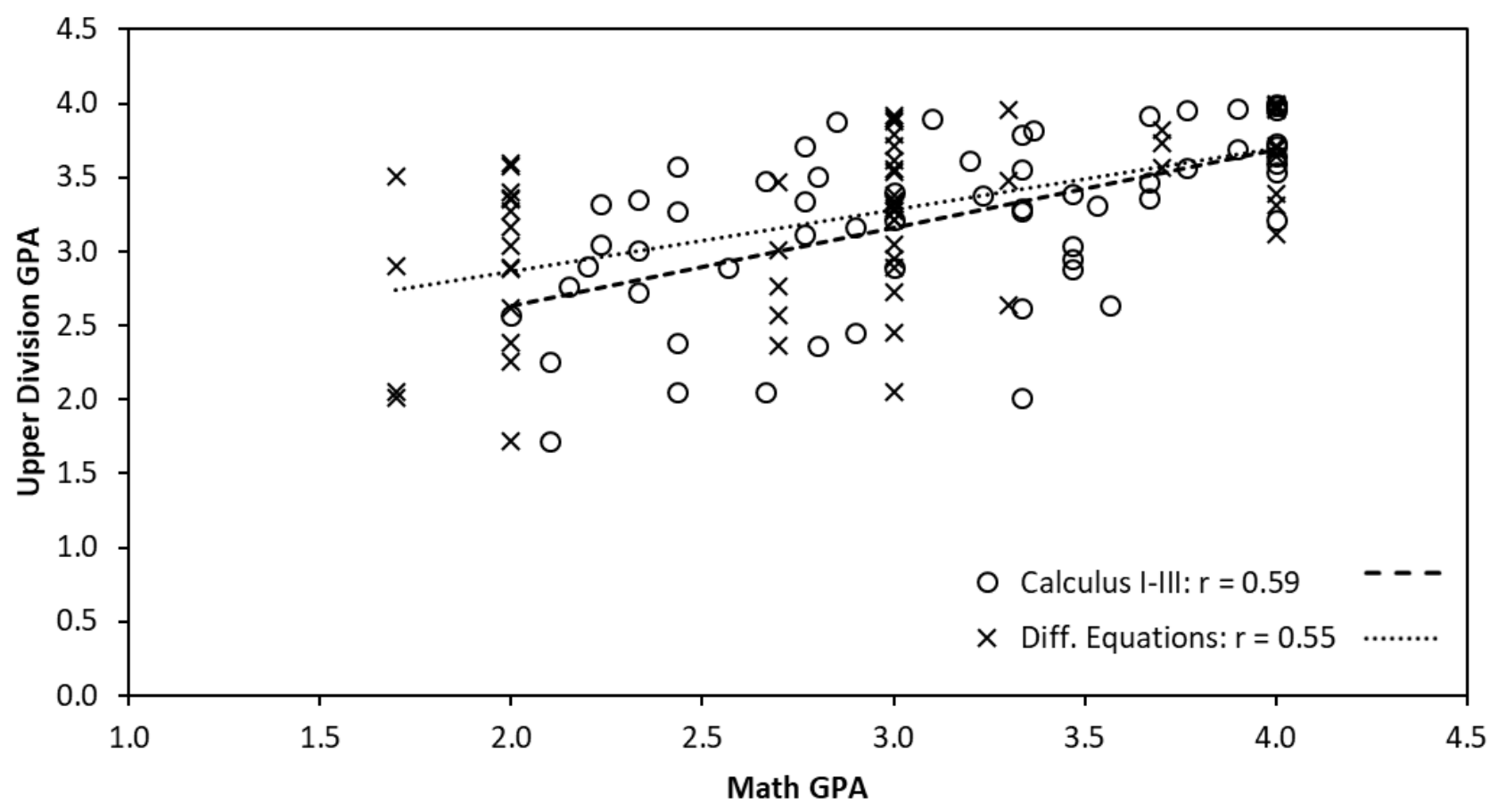

Figure 5: ME Upper Division GPA as a function of math course GPAs.

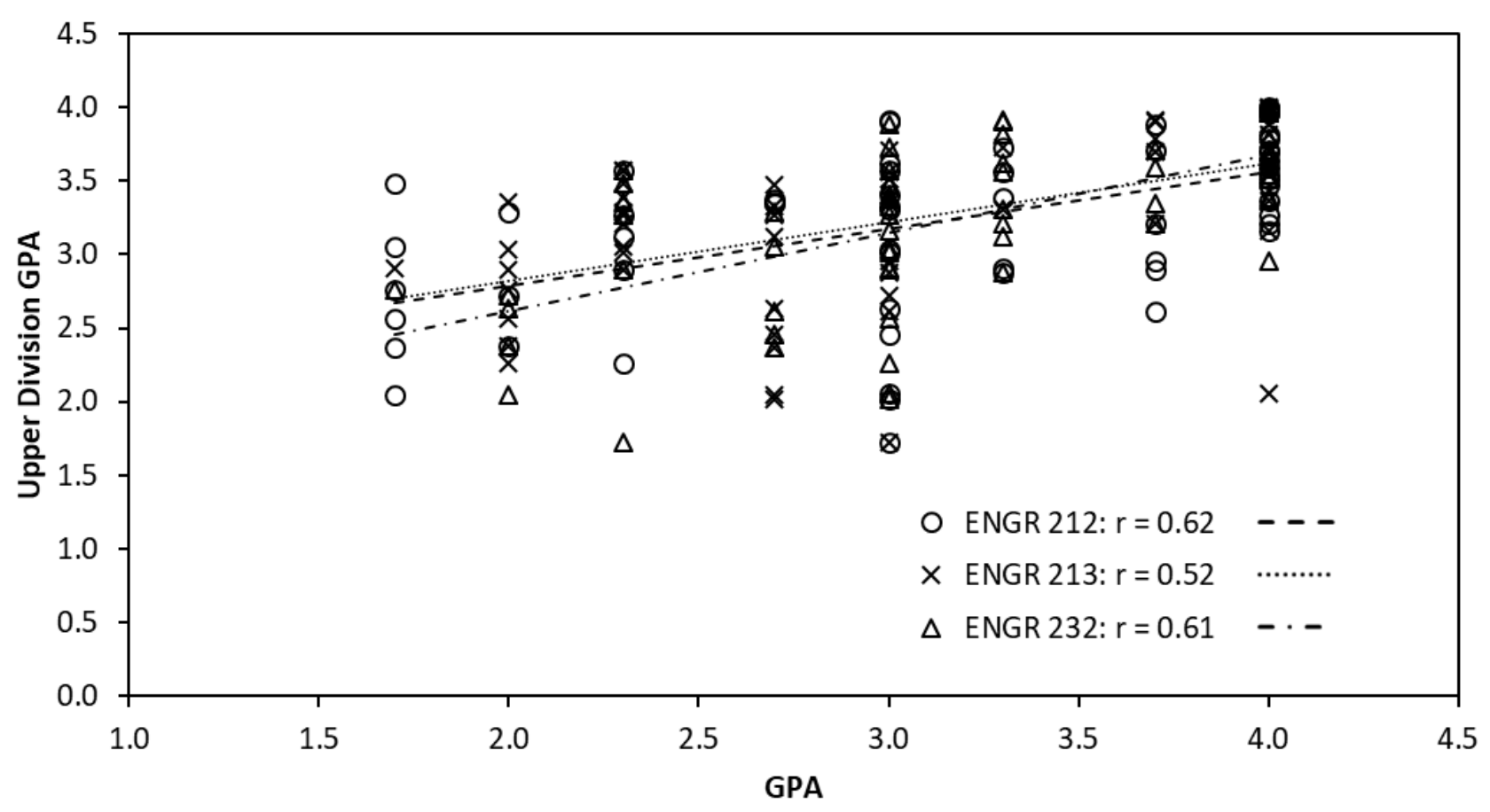

Figure 6: ME Upper Division GPA a function of mechanics course GPAs. 
Finally, the influence of ME Lower Division GPA on ME Upper Division GPA was studied. Figure 7 plots ME Upper Division GPA as a function of ME Lower Division GPA. A correlation of 0.68 was found between ME Lower Division GPA and ME Upper Division GPA. This is one of the stronger correlations found and it provides evidence for having prerequisite requirements as success in Lower Division courses effects performance in Upper Division courses. A summary of the correlation analysis is presented in Table 3.

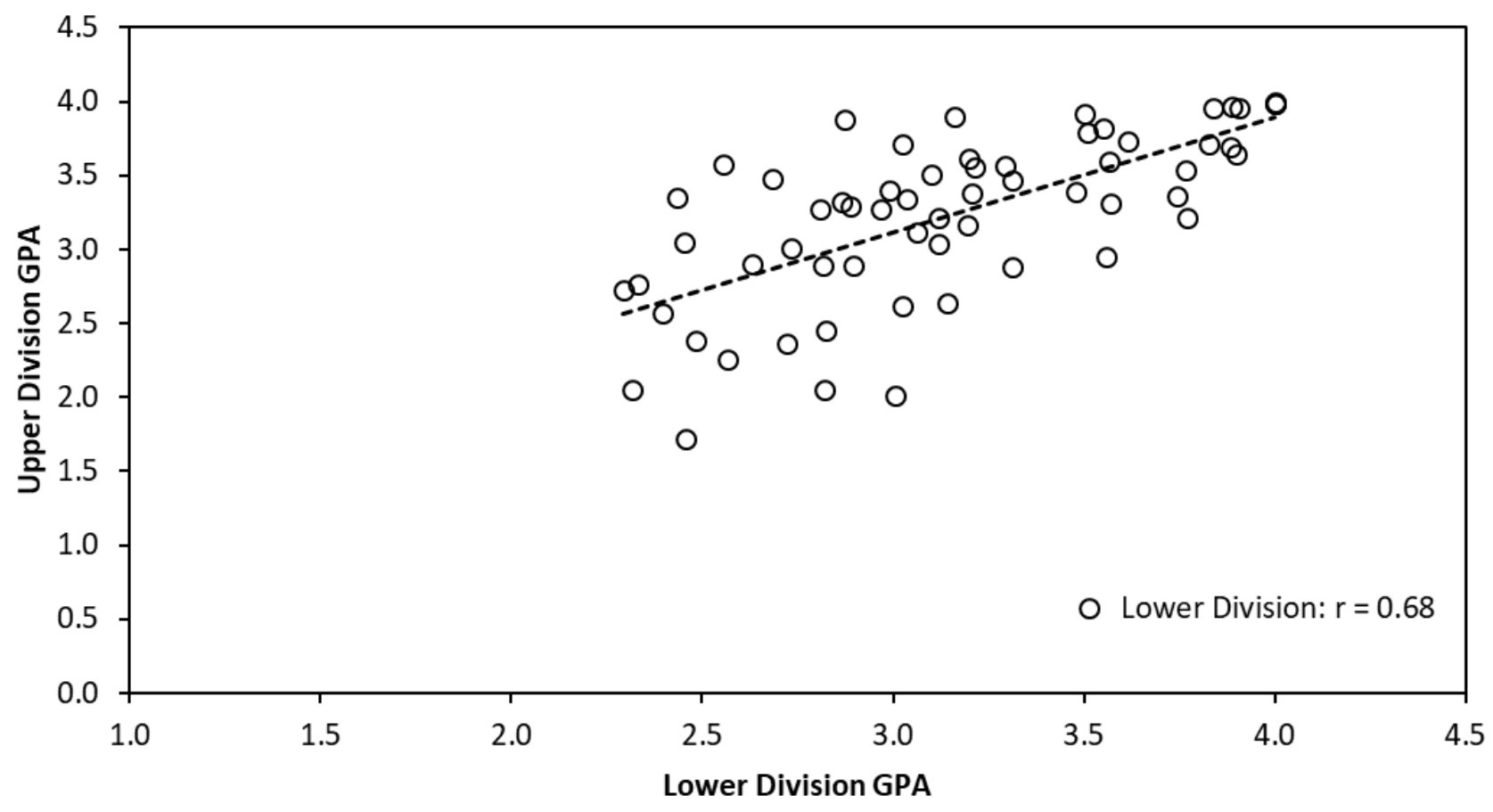

Figure 7: ME Upper Division GPA as a function of ME Lower Division GPA. 
Table 3: Summary of correlation analysis.

\begin{tabular}{|l|l|c|}
\hline \multicolumn{1}{|c|}{ Independent Variable } & \multicolumn{1}{|c|}{ Dependent Variable } & r \\
\hline SAT/ACT Math & Calculus I-III GPA & 0.41 \\
\hline SAT/ACT Math & Differential Equations GPA & 0.30 \\
\hline SAT/ACT Math & Physics GPA & 0.42 \\
\hline SAT/ACT Math & Chemistry GPA & 0.34 \\
\hline SAT/ACT Math & ENGR 212 GPA & 0.24 \\
\hline SAT/ACT Math & ENGR 213 GPA & 0.38 \\
\hline SAT/ACT Math & ENGR 232 GPA & 0.30 \\
\hline SAT/ACT Math & Mechanics GPA & 0.34 \\
\hline SAT/ACT Math & Circuits GPA & 0.60 \\
\hline SAT/ACT Math & ME Lower Division GPA & 0.40 \\
\hline SAT/ACT Math & ME Upper Division GPA & 0.42 \\
\hline SAT/ACT Math & University GPA & 0.50 \\
\hline High School GPA & SAT/ACT Math & 0.05 \\
\hline High School GPA & ME Lower Division GPA & 0.43 \\
\hline High School GPA & ME Upper Division GPA & 0.18 \\
\hline Calculus I-III GPA & ME Upper Division GPA & 0.59 \\
\hline Differential Equations GPA & ME Upper Division GPA & 0.55 \\
\hline Physics GPA & ME Upper Division GPA & 0.68 \\
\hline Chemistry GPA & ME Upper Division GPA & 0.43 \\
\hline ENGR 212 GPA & ME Upper Division GPA & 0.53 \\
\hline ENGR 213 GPA & ME Upper Division GPA & 0.52 \\
\hline ENGR 232 GPA & ME Upper Division GPA & 0.61 \\
\hline Mechanics GPA & ME Upper Division GPA & 0.62 \\
\hline Circuits GPA & ME Upper Division GPA & 0.57 \\
\hline ME Lower Division GPA & ME Upper Division GPA & 0.68 \\
\hline & & \\
\hline
\end{tabular}

\section{Multi-Variable Weighted Correlation}

A computer program was used to calculate linear coefficients for multi-variable correlations. The program used an increment of 0.01-0.05 for coefficient ranges of 300 values to iterate correlation calculations. The weighting factor, $a_{i}$, for each variable was determined for a linear fit following Equation (2).

$$
M E_{G P A}=a_{1} x_{1}+a_{2} x_{2}+\ldots+a_{i} x_{i}
$$

A series of iterations using the independent variables, $x_{i}$, listed in Table 4 were conducted to determine the coefficient of correlation for cumulative GPA in the ME Program. 
Table 4: Multivariable correlation with cumulative ME GPA.

\begin{tabular}{|c|c|c|c|c|c|c|c|c|c|}
\hline Test & $\begin{array}{c}\text { SAT } \\
\text { Math }\end{array}$ & $\begin{array}{c}\text { PHYS } \\
\text { GPA }\end{array}$ & $\begin{array}{c}\text { CALC } \\
\text { GPA }\end{array}$ & $\begin{array}{c}\text { Diff. } \\
\text { Eqs. }\end{array}$ & $\begin{array}{c}\text { MEx97 } \\
\text { GPA }\end{array}$ & $\begin{array}{c}\text { Lower } \\
\text { Div GPA }\end{array}$ & $\begin{array}{c}\text { Circuits } \\
\text { GPA }\end{array}$ & Increment & $\begin{array}{c}\text { Correlation } \\
\text { (r) }\end{array}$ \\
\hline 1 & 0 & 1.78 & 1.58 & 0 & 0 & 1.94 & 1.78 & 0.02 & 0.91 \\
\hline 2 & 0 & 1.70 & 0 & 0 & 0 & 1.54 & 0 & 0.01 & 0.86 \\
\hline 3 & 0 & 0 & 0 & 0 & 0 & 2.01 & 1.48 & 0.01 & 0.88 \\
\hline 4 & 0 & 2.76 & 2.09 & 0.70 & 0 & 0 & 0 & 0.01 & 0.88 \\
\hline 5 & 0 & 1.85 & 1.30 & 0.70 & 0 & 1.45 & 0 & 0.05 & 0.90 \\
\hline
\end{tabular}

As shown in Table 4, the strongest correlation $(r=0.91)$ occurred when ME Lower Division GPA was most heavily weighted, followed closely by average GPAs in Physics and Circuits. These results correspond with the higher correlations determined for these course groupings in the two-variable regression analysis and can be represented by Equation (3). In other words, higher coefficients in Table 4 correspond to variables that present stronger correlations with ME GPA. MEx97 GPAs were generally high due to team-based design projects heavily influencing course grade. Expectedly, student grades in these courses were much weaker indicators of success than course grades composed of individually completed assignments. SAT/ACT Math scores likely had weak correlations due to the difference in scale of the standardized exam and GPA. A normalization technique may have allowed the significance of SAT/ACT Math score to appear as a non-zero coefficient.

$$
M E_{G P A}=1.78\left(P H Y S_{G P A}\right)+1.58\left(C_{A L C} C_{G P A}\right)+1.94\left(\operatorname{LowDiv}_{G P A}\right)+1.78\left(\operatorname{Circuits}_{G P A}\right)
$$

Using the same computer program, a multi-variable correlation analysis was conducted to determine coefficients for the same independent variables when compared with ME Upper Division GPA. The results shown in Table 5 indicate that ME Lower Division GPA should receive the heaviest weighting when predicting academic performance in ME Upper Division.

Table 5: Multivariable correlation with ME Upper Division GPA.

\begin{tabular}{|c|c|c|c|c|c|c|c|c|c|}
\hline Test & $\begin{array}{c}\text { SAT } \\
\text { Math }\end{array}$ & $\begin{array}{c}\text { PHYS } \\
\text { GPA }\end{array}$ & $\begin{array}{c}\text { CALC } \\
\text { GPA }\end{array}$ & $\begin{array}{c}\text { Diff. } \\
\text { Eqs. }\end{array}$ & $\begin{array}{c}\text { MEx97 } \\
\text { GPA }\end{array}$ & $\begin{array}{c}\text { Lower } \\
\text { Div GPA }\end{array}$ & $\begin{array}{c}\text { Circuits } \\
\text { GPA }\end{array}$ & Increment & $\begin{array}{c}\text { Correlation } \\
\text { (r) }\end{array}$ \\
\hline 1 & 0 & 1.94 & 0.90 & 0 & 0 & 2.82 & 1.26 & 0.02 & 0.75 \\
\hline 2 & 0 & 2.08 & 0 & 0 & 0 & 2.84 & 0 & 0.01 & 0.73 \\
\hline 3 & 0 & 0 & 0 & 0 & 0 & 1.89 & 0.78 & 0.01 & 0.73 \\
\hline 4 & 0 & 2.00 & 1.27 & 0.2 & 0 & 0 & 0 & 0.01 & 0.72 \\
\hline 5 & 0 & 1.75 & 0.9 & 0.7 & 0 & 2.90 & 0 & 0.05 & 0.75 \\
\hline 6 & 0 & 1.70 & 0.95 & 0 & 0 & 2.0 & 0 & 0.05 & 0.74 \\
\hline
\end{tabular}

Equation (4) provides a correlation coefficient of $r=0.75$ with ME Upper Division GPA.

$$
U p D i v_{G P A}=1.75\left(P H Y S_{G P A}\right)+0.9\left(C A L C_{G P A}\right)+0.7\left(\text { DiffEq }_{G P A}\right)+2.9\left(\operatorname{LowDiv}_{G P A}\right)
$$




\section{Implications and Conclusions}

The correlation data presented in this study demonstrate that SAT/ACT math score and high school GPA have no correlation $(r=0.05)$, and SAT/ACT math score has a much higher correlation with success in the ME Program than high school GPA. This result supports the importance of SAT/ACT math score as an admission criterion for students entering the ME program as freshmen. The SAT/ACT math score had a 50\% correlation with overall university GPA, which also supported using the standardized test score component as a measure of student success not only in the ME program, but at the University of Evansville as a whole. The lack of correlation of high school GPA with SAT/ACT math score suggests the measure is not a good indicator of mathematical preparedness or aptitude. It should be noted that only four of the reported high school GPAs were less than 3.0.

SAT/ACT math score had a lower correlation than expected with the Lower Division mechanics courses, which are math-intensive. Student GPA in Circuits I and II had the highest correlation with SAT/ACT math score $(r=0.60)$, and a relatively high correlation with Upper Division GPA $(r=0.57)$. Student GPA in Physics I and II tied for the highest correlation with Upper Division GPA $(r=0.68)$ and had one of the strongest correlations with SAT/ACT math score $(r$ $=0.42$ ). Together, these results support SAT/ACT math score as one of the strongest indicators of student potential for success in all four years of undergraduate study. The results also reinforce the notion that student success in math and science (physics) courses suggest potential for success in engineering.

After two years of undergraduate study in the ME program, overall Lower Division GPA and Physics GPA demonstrated the highest correlation with student success in Upper Division $(r=$ 0.68). Average GPA in the Lower Division mechanics courses exhibited the second highest correlation with Upper Division success $(r=0.62)$. As expected, these results suggest that strong academic performance in foundational courses support success in higher level ME courses. These results also support the use of pre-requisite requirements for courses and a minimum Lower Division GPA requirement for admission to Upper Division.

Based on this study, SAT/ACT math minimums demonstrate potential for student success in the ME program better than high school GPA. Academic performance in Lower Division courses is linked to success in Upper Division courses, and thus success in the program. The results support requiring students to demonstrate nominal measures of academic preparedness before enrolling in higher level courses. An Upper Division admission requirement delineates minimum levels of academic preparedness for students and faculty to evaluate potential for success in upper level courses. Instating admissions requirements at both the pre-college and early college levels bolster student success and potential retention rates while limiting strain on resources that would occur from admitting ill-prepared students.

While the results presented are limited, the authors believe the overall findings are transferable to other institutions. ABET accreditation guidelines require some level of homogeneity across undergraduate programs for mechanical engineering; while specifics within the curricula may vary, considerable overlap should exist within the major. The Lower Division mechanics courses are foundational for many mechanical engineering courses, which increases the likelihood of 
transferability. Additionally, most U.S. institutions require standardized exam scores and high school transcripts from incoming students, which establishes a common set of performance predictors for any program. Overall university GPA is less transferable due to multiple classifications of institutions that offer a BSME, and the highly variable general education programs, if required. However, comparisons to ME GPA maintain commonalities across institutions.

\section{Limitations of Study}

The study was limited to three most recent graduating classes from the ME program at the University of Evansville, resulting a total sample of 61 students. The sample included 7 females, 3 international students, and 3 transfer students. Measures of student performance were not available for all students in the selected graduating classes; high school data for transfer students and international students were not on record or not easily converted to US measures. Therefore, the results primarily describe domestic, non-transfer students. Only students that completed all BSME degree requirements were included in the study. The selected data set provided sample sizes greater than 40 , but conclusions would be more robust with a larger and more diverse data set.

UE has a graduation requirement of an overall GPA of 2.0, and a GPA of 2.0 within the major, which artificially places a lower limit on student performance in this study. The ME program requires a minimum Lower Division GPA of 2.5, which also imposes a lower limit on student performance measures. At UE students have the option to re-take a course, which replaces the course grade counting towards GPA. For this study, the final grade recorded on a student's official transcript was used in the analysis. Multiple attempts at a course were not accounted for.

The authors acknowledge that additional factors may provide more insight on student success both in college and after graduation. Post-graduation success was beyond the scope of this study, and pre-college factors, such as high school math and science courses, varied significantly for each student. Additional data regarding students that did not complete the degree requirements could yield indicators for attrition. Co-curricular, extra-curricular, volunteer, employment, and professional activities were also excluded from this study.

\section{Future Work}

This study can be expanded in the future by including a more robust data set (size and diversity). With a more robust data set, performance measures could be analyzed to determine if correlations with success varied based on student demographics. A larger sample of transfer student statistics may provide results useful for effective articulation agreements with other institutions, including community colleges.

Tracking students that do not complete the BSME degree requirements could provide insight on course performance links to leaving the program. If student performance in one course strongly correlated to students leaving the program, retention boosting efforts could be designed around that course. 
Pre-college measures of performance were limited to high school GPA and SAT/ACT math scores in this study. Future work would include high school class rank, class size, and high school institutional ranking as weighted factors in a multi-variate analysis.

\section{References}

[1] H. O. Aintablian and T. Ghirmai, "Correlation of admission data to undergraduate student success in electrical engineering," in American Society for Engineering Education Conference, Columbus, 2017.

[2] E. Cohn, S. Cohn, D. C. Balch and J. J. Bradley, "Determinants of undergraduate GPAs: SAT scores, high-school GPA and high-school rank," Economics of Education Review, vol. 23, no. 6, pp. 577-586, 2004.

[3] T. Coyle, A. Snyder, D. Pillow and P. Kochunov, "SAT Predicts GPA better for high ability subjects: implications for Spearman's Law of Diminishing Returns," Personality and Inividual Differences, vol. 50, no. 4, pp. 470-474, 2011.

[4] P. Cyrenne and A. Chan, "High school grades and university performance: a case study," Economics of Education Review, vol. 31, no. 5, pp. 524-542, 2012.

[5] C. Veenstra and G. D. Herrin, "Using the SAT and ACT scores for placement into engineering freshman courses," in American Society for Engineering Education Conference, Chicago, 2006.

[6] S. X. Niu and M. Tienda, "Test Scores, Class Rank and College Performance: Lessons for Broadening Access and Promoting Success," Rassegna Italiana Di Sociologia, vol. 2, pp. 199-226, 2016.

[7] D. W. Stamps, "A Vertically Integrated Design Sequence," International Journal of Engineering Education, vol. 29, no. 6, pp. 1580-1590, 2013.

[8] M. E. Program, "Admission to Lower Division of Mechanical Engineering," University of Evansville, [Online]. Available:

https://www.evansville.edu/majors/mechanicalengineering/lower.cfm.

[9] M. E. Program, "Admission to Upper Division of Mechanical Engineering," University of Evansville, [Online]. Available:

https://www.evansville.edu/majors/mechanicalengineering/upper.cfm.

[10] N. J. Dorans, "Correspondences Between ACT and SAT I Scores," College Board Publications, New York, 1999.

[11] J. L. Devore, Probability and Statistics for Engineering and the Sciences, Boston, MA: Cengage Learning, 2016. 